\title{
A low-cost electronic tensiometer system for continuous monitoring of soil water potential
}

\author{
Martin Thalheimer \\ Research Centre for Agriculture and Forestry Laimburg, Bolzano, Italy
}

\begin{abstract}
A low cost system for measuring soil water potential and data logging was developed on the basis of an Arduino microcontroller board, electronic pressure transducers and water-filled tensiometers. The assembly of this system requires only minimal soldering, limited to the wiring of the power supply and the pressure sensors to the microcontroller board. The system presented here is, therefore, not only inexpensive, but also suited for easy reproduction by users with only basic technical skills. The utility and reliability of the system was tested in a commercial apple orchard.
\end{abstract}

\section{Introduction}

Increasingly, problems related to water resources are the cause of limitations in agriculture. Therefore, the availability of simple yet accurate tools for monitoring plant-available water and scheduling irrigation will become a key factor for saving significant amounts of water and energy while maintaining, or even improving, yield and quality of agricultural produce in many climatic regions of the world.

For many decades, this topic has been the subject of intensive research, and a wide range of methods for monitoring soil moisture has been proposed (Evett, 2008). These include techniques to measure soil water content or potential as well as soil water budgets calculated on the basis of soil, plant, and climatic data.

Tensiometers are the only instruments capable of providing a direct measurement of soil matric potential due to the hydraulic connection

Correspondence: Martin Thalheimer, Research Center for Agriculture and Forestry Laimburg, Laimburg 6, 39040 Auer/Ora (BZ), Italy.

Tel: +39.0471 .969652 .

E-mail: martin.thalheimer@provinz.bz.it

Key words: soil water potential, microcontroller, pressure transducer, tensiometer, data logging, Arduino.

Received for publication: 28 August 2013.

Accepted for publication: 6 November 2013.

(C) Copyright M. Thalheimer, 2013

Licensee PAGEPress, Italy

Journal of Agricultural Engineering 2013; XLIV:e16

doi:10.4081/jae.2013.e16

This article is distributed under the terms of the Creative Commons Attribution Noncommercial License (by-nc 3.0) which permits any noncommercial use, distribution, and reproduction in any medium, provided the original author(s) and source are credited. between soil water and the water inside the tensiometer shaft. Soil water potential is thus translated into a negative pressure inside the tensiometer that can be sensed by a mechanical gauge or electronic pressure sensor. At equilibrium, the partial vacuum inside the tensiometer equals the sum of soil matric potential plus the usually negligible effect of the height of the tensiometer's water column. Because of the direct relation of matric water potential to plant water availability, tensiometers require no site-specific calibration and are, therefore, well suited for a wide range of applications in soil hydrology and irrigation management. A frequently mentioned inconvenience of conventional water-filled tensiometers is their limited range of operation, typically within 0 to $-80 \mathrm{kPa}$. However, most crops present their soil moisture optimum well within this limit (Gratton and Oster, 1992; Sanders, 1997; Thompson et al., 2007). Tensiometers are, therefore, an excellent tool for optimizing water-use efficiency of a multitude of agricultural and horticultural crops. Electronic devices have made it possible to implement systems of automatic data acquisition and irrigation control. Commercially available systems are, however, often expensive and sometimes complicated to operate. Recent advances in electronics have led to the development of inexpensive components which can be assembled into fully operational sensing, monitoring, and control systems (Dedrick et al., 2000; Fisher and Gould, 2012; Fisher and Kebede, 2010; Greswell et al., 2009; Riley et al., 2006).

The main objective of this paper is to propose an easily reproducible, low cost tensiometer system that requires minimal soldering of electronic components. It describes the technical layout and the assembly of the electronic unit as well as the assembly of the tensiometers from easily available materials. The presented system is based on the opensource microcontroller platform, Arduino, and a few additional components, and it is designed to accomplish accurate measurements of soil matric potential at regular intervals and to store data in memory for later retrieval. A suitable software code for the microcontroller is freely available. The system has been successfully tested for research purposes and in commercial fruit production.

While combinations of data loggers and electronic tensiometers have been commercially available for many years, their cost has restricted their use mainly to research purposes or high value crops. The very limited cost of the system presented in this paper could represent a step towards a more widespread application of accurate monitoring of soil water potential, leading to an improvement of water use efficiency in many fields of agricultural production.

\section{Materials and methods}

The core of the data acquisition and logging system presented here consists of a microcontroller board and a variable number of electronic pressure transducers. Power for prolonged standalone use is provided by a small solar panel and a re-chargeable lead acid battery. The hardware components are shown in Figure 1 and the schematic diagram of the circuit is presented in Figure 2. 


\section{Microcontroller board}

There is a wide choice of commercially available microcontrollers. Most of them require additional external components and/or specific programming interfaces to become fully operational units, and therefore demand a substantial degree of technical expertise both for assembly and programming. In recent years, an open source project has been launched, designed to make the use of microcontrollers in multidisciplinary projects more easily accessible. The Arduino system consists of boards equipped with Atmel AVR microcontrollers and complementary components needed for regulated power supply, serial communication and interfacing with external hardware. The microcontroller is equipped with a bootloader, which enables programming via opensource PC software without additional specific hardware.

The presented technical layout is based on an Arduino board with an Atmega328 microcontroller and 5V power supply. The Atmega328 features 6 analogue (A/D) ports (10 bit resolution) with an input range of 0-5 V, 14 digital input/output ports, and $32 \mathrm{~KB}$ of flash memory, as well as $1 \mathrm{~KB}$ EEPROM. Each A/D port of the microcontroller can be used as input for an electronic pressure sensor, thus allowing a maximum of 6 tensiometers per unit.

As with the hardware, the Arduino integrated development environment is open source and can be down-loaded freely from the project's internet website (http://www.arduino.cc). This application is written in Java and, besides providing the environment for programming, serves for compiling and up-loading programs to the microcontroller. Programmes are written in a language similar to $\mathrm{C} / \mathrm{C}++$, with some simplifications and modifications. Detailed reference about boards and the programming language, including explanatory examples, can be found on the Arduino website (http:/www.arduino.cc).

\section{Electronic pressure transducers}

The type of sensor used for this application is the piezoresistive differential pressure transducer MPX5100DP from Freescale Semiconductor with integrated temperature compensation and signal amplification circuits, providing a linear voltage output for a differential pressure range from 0 to $100 \mathrm{kPa}$. The sensitivity of the sensor corresponds to $45 \mathrm{mV} / \mathrm{kPa}$, according to the official product datasheet (Freescale Semiconductor, 2010).

The MPX5100DP sensor requires a power supply of $5 \mathrm{~V}$ and provides an output voltage with a full-scale span of $4.5 \mathrm{~V}$ and a maximum output of $4.8 \mathrm{~V}$. MPX5100DP sensors have been used for various scientific tensiometer applications for more than a decade (Testezlaf et al., 1999; Thalheimer, 2003; Grashey-Jansen, 2012).

In order to verify the official data about the sensitivity of the sensor, a detailed output analysis over a differential pressure range of from 0 to $650 \mathrm{hPa}$ was performed on a randomly chosen MPX5100DP sensor. The output curve in Figure 3 was established with the hanging water column technique, measuring the sensor output at successive increases in the height of a hanging water column, thus creating an increasingly negative pressure at the sensor level.

For this purpose, several metres length of a water filled, transparent $3 \times 5 \mathrm{~mm}$ flexible PVC tubing were attached to the vacuum port of the sensor and arranged into a U-shape. The free end of the tube was shifted vertically downwards in successive steps such as to move the water meniscus in the tube from its initial position at the same height of the sensor to increasingly lower positions. Sensor readings were taken at each step of $10 \mathrm{~cm}$ until a final height of the hanging water column of $650 \mathrm{~cm}$ was reached. The pressure difference $(\Delta \mathrm{P})$ relative to atmospheric pressure at each step of the procedure was calculated according to the following formula:

$$
\Delta \mathrm{P}=\mathrm{h}_{\mathrm{w}} \mathrm{g} \rho_{\mathrm{w}}
$$

where:

$h_{w}$ is the height of the hanging water column between the sensor level and the water meniscus in the tube;

$\mathrm{g}$ the gravitational force;

$\rho_{w}$ the density of water.

The resulting calibration function (Figure 3 ) describes a perfect linearity between pressure differential and sensor output $\left(r^{2}=1\right)$. The experimentally established sensitivity of the sensor was of $44 \mathrm{mV} / \mathrm{kPa}$, thus coming very close to the sensitivity of $45 \mathrm{mV} / \mathrm{kPa}$ stated in the official technical datasheet.

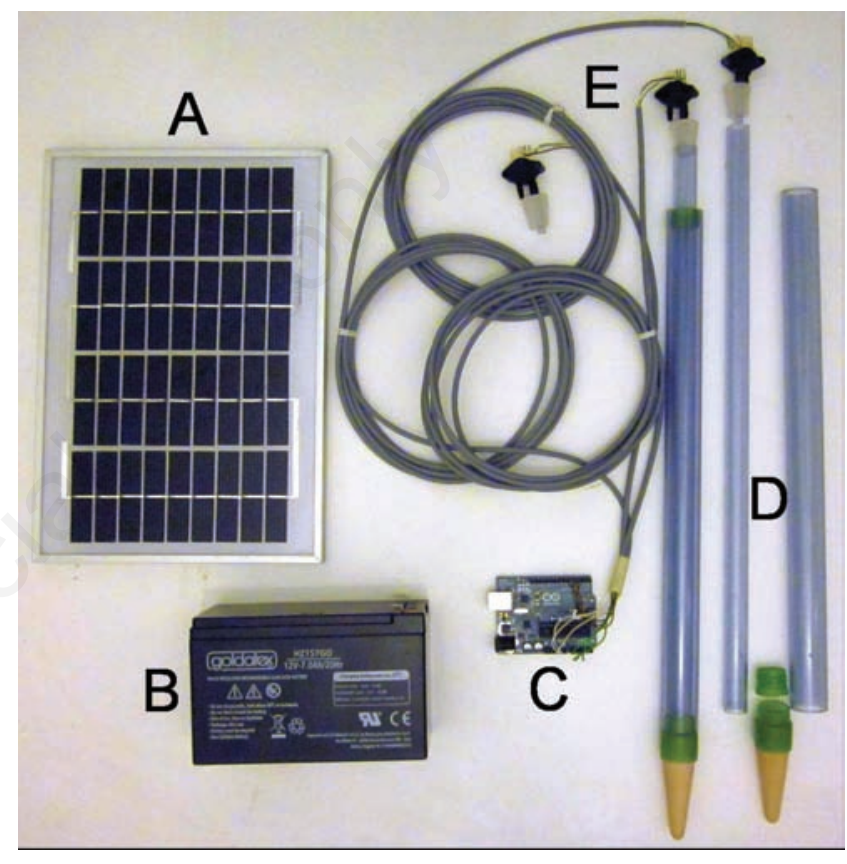

Figure 1. Tensiometer station hardware: (A) photovoltaic panel, (B) re-chargeable battery, (C) Arduino board, (D) assembled (left) and unassembled (right) tensiometer, (E) pressure transducers wired to the controller board.

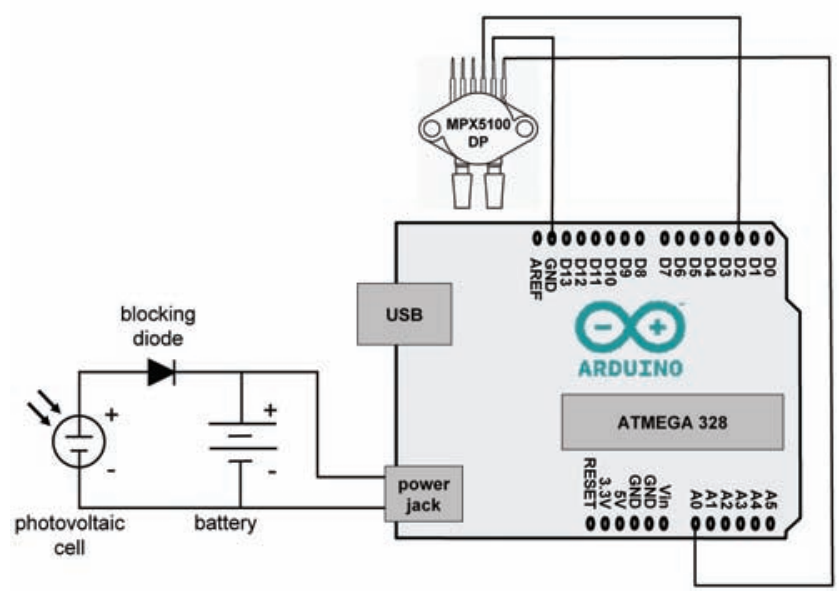

Figure 2. Electrical scheme of the tensiometer logging system. 


\section{Power supply}

The power consumption of different Arduino and compatible boards varies according to their specific technical design. Standard Arduino boards are generally equipped with a number of components not strictly necessary for standalone operation, such as LEDs and communication interfaces, resulting in a typical power consumption of around $25 \mathrm{~mA}$. Arduino boards with reduced external circuitry, e.g. without the USB interface, have a slightly lower power consumption of around $15 \mathrm{~mA}$.

The MPX5100DP pressure transducers require a supply current of typically $7 \mathrm{~mA}$ (max. $10 \mathrm{~mA}$ ). In the present system, the pressure sensors are each powered individually by a digital port of the microcontroller, thus restricting the power supply to the pressure sensors only to the short time necessary for each tensiometer reading to be taken.

Further substantial reductions in power consumption are technically possible, such as implementing a sleep-mode of the microcontroller in conjunction with an external real-time clock, as proposed in various similar projects (Afanasyev, 2004; Fisher, 2007; Fisher and Gould, 2012; Fisher and Kebede, 2010). However, in accordance with the outlined objective of maximum simplicity and ease of replication, preference was given to a combination of a small photovoltaic panel (5W/12V) and a re-chargeable battery of appropriate size (6Ah) to provide sufficient power for continuous and long-term operation of the unit. The solar panel can be directly connected to the battery without any further charge control circuit, if the output current of the panel remains within $10 \%$ of the battery's storage capacity. If not already provided on the panel, only a blocking diode needs to be added in order to prevent reverse flow of current from the battery through the solar module during darkness (Figure 2).

\section{Data storage and transfer}

The Atmega328 is equipped with a 1 Kbyte EEPROM that can be used for data storage. This may not seem very much compared to the storage capacities of other modern electronic devices, but can provide sufficient memory for many practical applications. In the case of a configuration with 3 tensiometers and an hourly interval of data-logging, the 1 Kbyte EEPROM provides data storage for approximately two weeks. Setting longer intervals between consecutive readings will increase the logging autonomy accordingly. Data storage capacity could also be increased by adding an external EEPROM, but this would again involve a more complex technical design and, therefore, go beyond the scope of this project.

Data can be downloaded from the microcontroller board to the PC via a serial connection. Most types of Arduino boards are already equipped with the required electronic interface. Simpler boards without serial interface need an external adapter for converting the microcontroller's TTL levels to signals compatible with the PC serial port. On the PC, a suitable terminal programme (e.g. Hyper Terminal) makes it possible to retrieve and save the data transferred from the microcontroller's memory.

\section{Assembly of the electronic unit}

The assembly of the electronic hardware requires only the wiring of the power supply and the electronic pressure sensors to the Arduino board. On the sensor side, a 3-conductor cable is soldered to pins 1-3 of each pressure transducer. The other ends of the cable are connected to the appropriate pins of the Arduino board, as listed in Table 1.

\section{Tensiometer assembly}

Tensiometers were assembled from commercially available porous ceramic cups (Tropf-Blumat, Weninger Kunststoff - Keramikwerk, Austria; http://www.blumat.at) and transparent PVC pipes of suitable diameter and length. A 16-mm outer diameter PVC pipe of desired length was fixed with hot-melt adhesive inside the plastic neck of a porous ceramic cup. The threaded end of the plastic neck had been cut off previously. Optionally, a piece of 25 -mm outer diameter PVC pipe can be added externally in order to obtain a tensiometer of the same external diameter as that of the ceramic cup (Figure 4A).

The air entry point of the abovementioned ceramic cups was determined by direct observation on a representative number of specimens and was found to be typically within the range of 650 to $850 \mathrm{hPa}$. The cups present a hydraulic conductivity that is sufficiently high to allow rapid response to soil wetting as shown in Figure 5 by the sudden increases of soil matric potential after events of consistent rainfall.

The electronic pressure sensors were fitted onto silicone stoppers that serve to open/close the tensiometers for water filling. The silicone stoppers of appropriate size were perforated and a piece of $3 \times 5 \mathrm{~mm}$ flexible PVC tubing inserted and trimmed to a length of approximately $10 \mathrm{~mm}$ protruding at the upper side of the stopper. Finally, the electronic pressure transducer was inserted with its vacuum nipple into the upper end of this tubing (Figure 4B).

\section{Software code}

A software code for this tensiometer station is freely available directly from the Author on request. The code consists of a simple clock and calendar schedule based on the microcontroller's internal time counter. The programme carries out tensiometer readings at regular time intervals, which can be set to different values (1-2-3-4-6-8-12-24 h) by accessing the user menu provided in the software. An average value is obtained by calculating the arithmetic mean of 10 individual measurements of each tensiometer, replicated at short intervals. To optimize

Table 1. Pin connection between MPX5100DP sensors and the Arduino board. Port numbers in brackets correspond to the wiring example shown in Figure 2.

\begin{tabular}{ll} 
MPX5100DP & Arduino \\
1. Signal (notched) & AD port (0) \\
2. GND & GND \\
\hline 3. Power supply & Digital port (2) \\
\hline
\end{tabular}

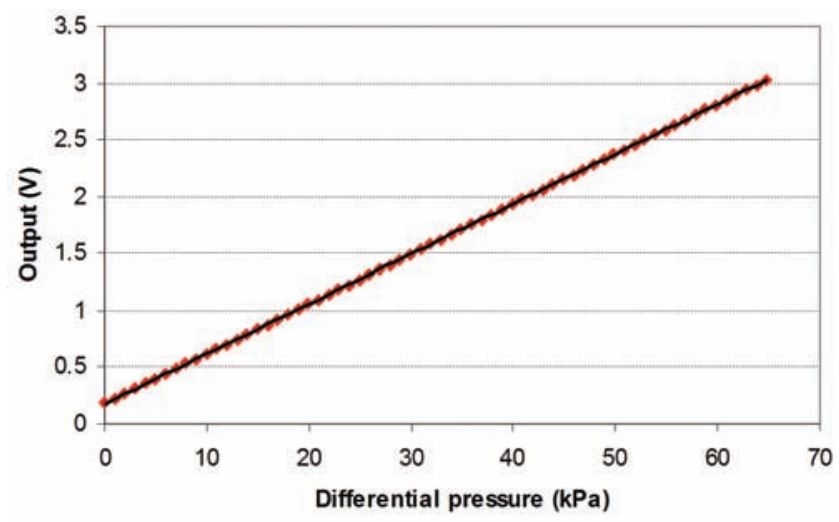

Figure 3. Experimental calibration curve of an MPX5100DP sensor. The slope of the linear regression of sensor output versus pressure (sensor sensitivity) is $44 \mathrm{mV} / \mathrm{kPa}\left(\mathrm{r}^{2}=1\right)$. 
memory use, the A/D readings of the pressure transducers are reduced from their original 10 bit to 8 bit resolution before storage. The data transfer function of the programme retrieves the data from the memory, transforms the original $\mathrm{A} / \mathrm{D}$ values to pressure units $(\mathrm{hPa})$ on the basis of the typical calibration function provided by the manufacturer of the pressure transducer (Freescale Semiconductor, 2010) and finally sends them as absolute values to the serial port. The final resolution of the tensiometer data retrieved from the logger is $4-5 \mathrm{hPa}$, which is easily sufficient for most purposes of agricultural water management.

For setting time, date and logging interval, as well as for retrieving or erasing data from the memory, a simple menu can be accessed via a serial connection with a PC. This menu also offers the options of reading actual tensiometer values and the current software settings at any given time. Furthermore, the menu offers the option of setting a threshold value for the tensiometer readings of soil water potential. At any periodic tensiometer reading, the measured values are compared to the chosen threshold and if, in terms of absolute values, soil water tension reaches or passes the threshold, the LED connected to digital pin 13, which is present on most Arduino boards, starts blinking, thus giving a visual indication e.g. for the need of irrigation. Vice versa, blinking will stop again as soon as tensiometer readings return below the set threshold.

The freely available software code contains further operational details in the form of comments.

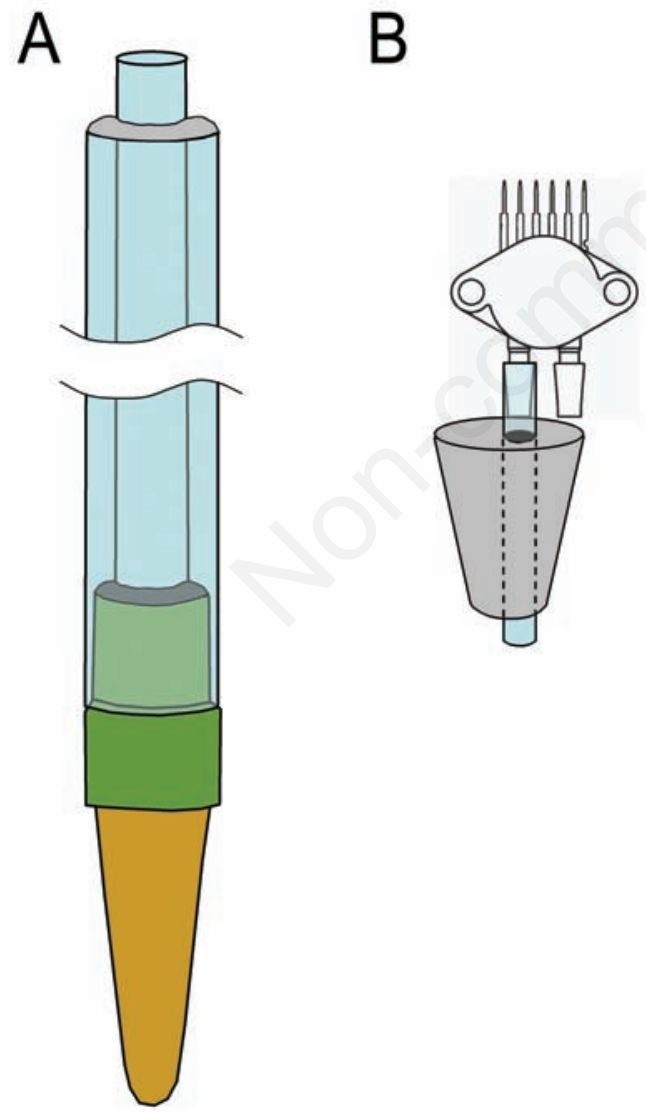

Figure 4. Schematic presentation of tensiometer makeup: (A) tensiometer shaft consisting of a $25 \mathrm{~mm}$ outer and $16 \mathrm{~mm}$ inner PVC pipe, both connected to a ceramic cup; (B) silicone stopper with inserted pressure transducer. Relative size of the two objects not in scale.

\section{Results}

\section{Apple orchard case study}

A tensiometer station of the described design on the basis of an Arduino Uno board, and with the logging interval set to $1 \mathrm{~h}$, was installed during the growing season 2012 in an apple orchard at the Research Centre for Agriculture and Forestry Laimburg in Northern Italy (Figures 6 and 7). Three tensiometers were placed along a tree

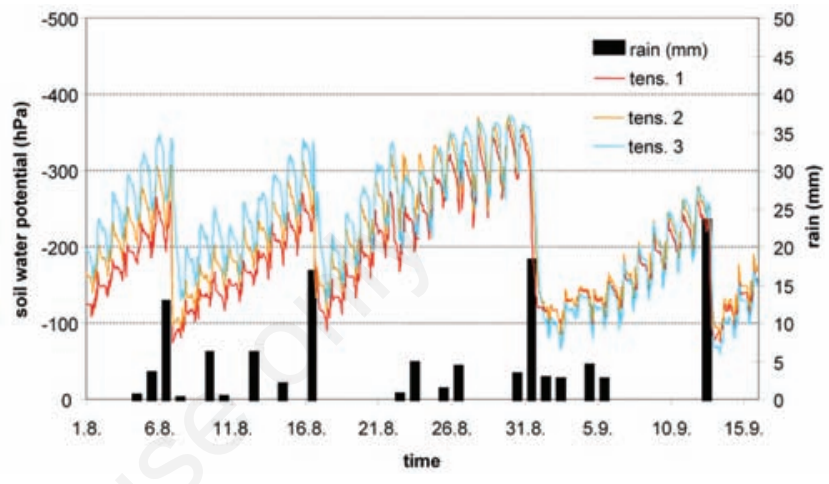

Figure 5. Soil water potential recorded by 3 tensiometers at a depth of $25 \mathrm{~cm}$ and daily rainfall for a 6-week period during the growing season 2012 in a high-density apple orchard.

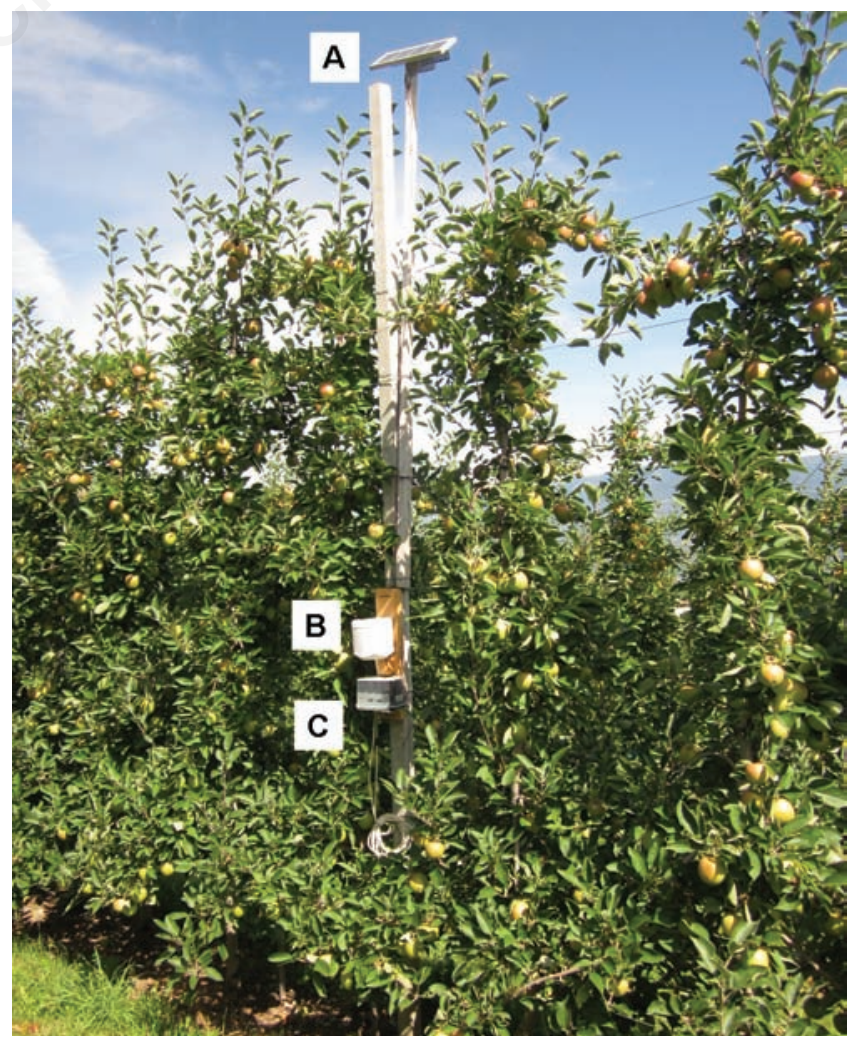

Figure 6. An electronic tensiometer station installed in an apple orchard. (A) Photovoltaic panel. (B and C) Microcontroller board and battery, both under protective cover. The tensiometers are hidden by the trees. 
row at a distance of approximately $2 \mathrm{~m}$ from each other and with their ceramic cups at a depth of $25 \mathrm{~cm}$, which corresponds to the area of highest root density of intensive apple orchards on dwarfing rootstocks. The Arduino board and the battery were mounted on a wooden support, which in its turn was fastened to a cement pole. The photovoltaic panel was mounted on the same pole, overlooking the tree canopies and facing south for optimal interception of solar irradiation. A plastic container of suitable size turned upside down over the Arduino board provided adequate protection against rainfall. Also, the battery was protected by a plastic cover.

Data were regularly retrieved to a mobile PC at intervals of no more than two weeks so as not to exceed the available data storage capacity. The pattern of soil water potential recorded by the tensiometer station during a 6-week period between the beginning of August and midSeptember 2012 is shown in Figure 5. The graph reveals the general pattern of decreasing soil water potential as a result of plant water uptake over time and sudden increases after rainfall events. The graph also indicates a marked pattern of daily fluctuations of tensiometer readings, which result from the diurnal temperature changes determining the contraction or expansion of the small air volume trapped in the upper part of the tensiometer shafts (Warrick et al., 1998).

During this period of observation, the soil water potential never reached levels conducive to plant water stress. The reason for this lays

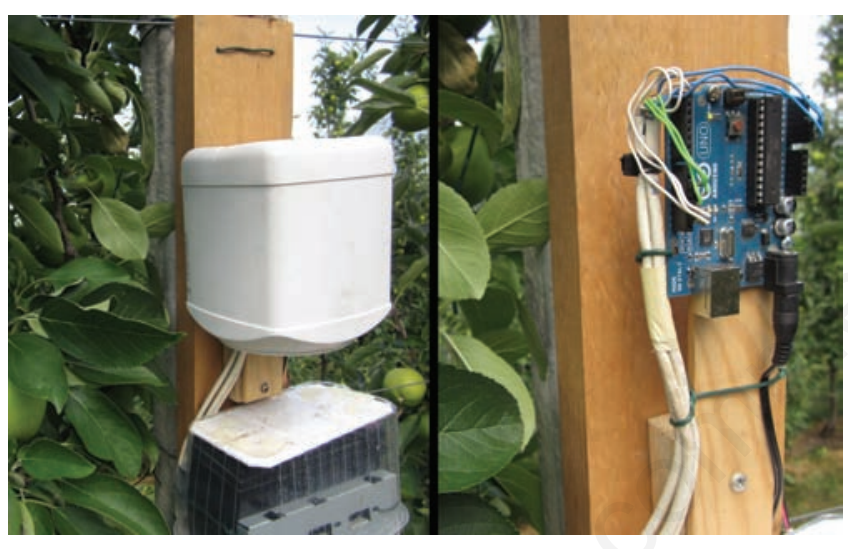

Figure 7. Detail of the tensiometer station shown in Figure 5, displaying the Arduino Uno board and battery with (left) and the Arduino board without (right) protective cover. The cables on the left lead to 3 tensiometers; the black cable on the right side connects to the $12 \mathrm{~V}$ battery.

Table 2. Indicative prices (without VAT and shipping) of the components of the electronic tensiometer system.

\begin{tabular}{lc} 
Part & Price $(€)$ \\
Microcontroller board and power supply & \\
Arduino Uno board & 23.5 \\
12V/6Ah sealed lead acid battery & 13.5 \\
5W/12V solar panel & 15 \\
Cable & 2 \\
Total & 52 \\
Tensiometer & \\
MPX5100DP pressure sensor & 13.6 \\
PVC pipes for a tensiometer of 50 cm length & 2.6 \\
Tropf-Blumat cone & 2.3 \\
Silicone stopper & 0.5 \\
Cable & 2 \\
Total & 21 \\
\hline
\end{tabular}

both in the well-distributed rainfall during the observation period and in the high water table which by capillary rise significantly contributes to satisfying the plants' water requirements at this site (Thalheimer, 2005). No irrigation was applied during this period of observation. This puts into clear evidence how the low-cost monitoring system presented here can effectively help to avoid unnecessary irrigation cycles or, in different circumstances, indicate the precise moment when irrigation is needed.

\section{Conclusions}

The proposed electronic data acquisition system for soil matric potential based on the open source Arduino system, MPX5100DP differential pressure sensors and self-assembled tensiometers, constitutes a very cost effective alternative to commercial soil moisture monitoring equipment. The prices of electronic components are in continuous evolution and can vary enormously depending on the source of supply and the order volume. An estimate of the cost of the components of the presented system is given in Table 2. For example, in the case of a configuration of the data acquisition system with three tensiometers, as used in the orchard test described, the estimate of the total cost of the system amounts to 115 euros.

From a technical point of view, the system has proved to be accurate and reliable, running for a test period of several months in two consecutive years without any malfunction. As for most electronic equipment, however, it cannot be excluded that under particular circumstances, such as strong electromagnetic fields generated by e.g. lightning discharge, the stability of the system may be compromised. Periodical controls of the units installed in the open field are, therefore, advisable.

From an agronomic viewpoint, the field testing in an apple orchard confirmed that the presented system has a high potential for substantially improving the efficiency of agricultural water use. This is made possible by the continuous monitoring of the availability of soil water for plant uptake and by the triggering of a visual signal indicating the precise moment when the need for irrigation arises. Furthermore, the data logging function allows the soil moisture pattern to be documented for prolonged periods and to carry out subsequent analyses of soil water dynamics as influenced by soil, climate, crop and irrigation.

The assembly of a tensiometer station of the described design requires only minimal soldering and can, therefore, be easily set up also by users with only basic technical skills. The simplicity of construction, combined with its modest cost, could make this system a useful tool for studies of soil hydrology in general and for irrigation management in particular.

\section{References}

Afanasyev V. 2004. A miniature daylight level and activity data recorder for tracking animals over long periods. Mem. Natl. Inst. Polar Res. 58:227-33.

Dedrick R.R., Halfman J.D., McKinney D.B. 2000. An inexpensive, microprocessor-based, data logging system. Comput. Geosci. 26:1059-66.

Evett S. 2008. Field estimation of soil water content: a practical guide to methods, instrumentation and sensors technology. Training Course Series No. 30, International Atomic Energy Agency, Vienna, Austria.

Fisher D.K. 2007. Automated collection of soil-moisture data with a lowcost microcontroller circuit. Appl. Eng. Agric. 23:493-500. 
Fisher D.K, Gould P.J. 2012. Open-source hardware is a low-cost alternative for scientific instrumentation and research. Modern Instrument. 1:8-20.

Fisher D.K., Kebede, H. 2010. A low-cost microcontroller-based system to monitor crop temperature and water status. Comput. Electr. Agric. 74:168-73.

Freescale Semiconductor. 2010. Technical Data Sheet for MPX5100. Rev 13, 05/2010. Available from: http://www.freescale.com/files/sensors/ doc/data_sheet/MPX5100.pdf?pspll=1

Grashey-Jansen S. 2012. Soil hydrology and soil properties on a partially reforested hillside in the Central Alps. J. Forest Sci. 58:363-71.

Gratton S.R., Oster J. 1992. Water quality guidelines for trees and vines. Drought Tips 92-38. Department of Land, Air and Water Resources, University of California, USA.

Greswell R., Ellis P., Cuthbert M., White R., Durand V. 2009. The design and application of an inexpensive pressure monitoring system for shallow water level measurement, tensiometry and piezometry. J. Hydrol. 373:416-25.

Riley T.C., Endreny T.A., Halfman J.D. 2006. Monitoring soil moisture and water table height with a low-cost data logger. Comput. Geosci. $32: 135-40$.
Sanders D.C. 1997. Vegetable crop irrigation. Horticulture Information Leaflet 33-E, North Carolina Cooperative Extension Service, North Carolina Sate University, USA.

Testezlaf R., Larsen C.A., Yeager T.H., Zazueta, F.S. 1999. Tensiometric monitoring of container substrate moisture status. Hort. Technol. 9:105-9.

Thalheimer M. 2003. Tensiometer modification for diminishing errors due to the fluctuating inner water column. Soil Sci. Soc. Am. J. 67:737-9.

Thalheimer M. 2005. Zur Dynamik des Bodenwassers an einem grundwassernahen Obstbau-Standort im Etschtal (Südtirol, Italien) [Soil water dynamics in an apple orchard with shallow groundwater table in the Adige Valley (South Tyrol, Italy)]. Laimburg J. 2:50-7.

Thompson R.B., Gallardo M., Valdez R.C., Fernández R.D. 2007. Using plant water status to define threshold values for irrigation management of vegetable crops using soil moisture sensors. Agric. Water Manage. 88:147-58.

Warrick A.W., Wierenga P.J., Young M.H., Musil S.A. 1998. Diurnal fluctuations of tensiometric readings due to surface temperature changes. Water Resour. Res. 34:2863-9. 